\title{
Ensino Híbrido: Novas Habilidades Docentes Mediadas pelos Recursos Tecnológicos
}

Hybrid Teaching: New Teacher Skills Mediated

Rozania Viana Miranda*1

Artur de Sousa Moret ${ }^{1}$

Jeferson Cardoso da Silva ${ }^{2}$

Berenice Perpetua Simão ${ }^{1}$

1 UNIR - Fundação Universidade Federal de Rondônia. Av. Presidente

Dutra, 2965, Centro. Porto Velho, RO

- Brasil.

2 Instituto Federal de Educação, Ciência

e Tecnologia de Rondônia-IFRO.

Av. Governador Jorge Teixeira 3146,

Setor Industrial. Porto Velho, RO -

Brasil.

*rozaniapvh@gmail.com

\section{Resumo}

A tecnologia tornou-se uma aliada quando o assunto é processo ensino-aprendizagem; é uma ferramenta para ajudar a personalizar as atividades em sala de aula; além disso, facilita no processo de aquisição de conhecimento dos alunos e professores. Contudo, é importante ressaltar que a tecnologia não substitui e nem diminui a presença do professor em sala apenas modifica seu papel nessa nova concepção de aprendizagem. Nesse sentido, esta pesquisa tem como objetivo realizar uma reflexão crítica sobre a proposta do ensino híbrido e as novas habilidades docentes mediadas pelos recursos tecnológicos. As variáveis selecionadas para análise foram Tecnologia, Metodologia de Ensino, Professor e Aluno. Conclui-se que esse novo cenário de aprendizagem favorece uma educação em que o aluno é o centro do processo, o professor é o mediador do conhecimento e, portanto, precisa mostrar aos alunos que existem diferentes formas de aprender e construir conhecimento.

Palavras-chave: Ensino híbrido. Papel do professor no ensino híbrido. Tecnologia no processo educacional.

\section{(6) 0}

Recebido 13/ 10/ 2019

\section{COMO CITAR ESTE ARTIGO}

ABNT: MIRANDA, R.V.;MORET,A.S.; DA SILVA, J.C.; SIMÃO;B.P. Ensino Híbrido: Novas Habilidades Docentes Mediadas pelos Recursos Tecnológicos. EaD em Foco, V10, e913. 2020. DOI: https://doi.org/10.18264/eadf.v10i913 


\section{Title Format of your Article in English}

\section{Abstract}

Technology has become an ally when it comes to the teaching-learning process. It is a tool to help personalize classroom activities and facilitates the knowledge acquisition process of students and teachers. However, it is important to emphasize that technology does not replace or diminish the presence of the teacher in the classroom, as it only modifies its role in this new conception of learning. In this sense, this research aims to investigate through the proposal of hybrid teaching: New teaching skills mediated by technological resources. The variables selected for analysis involving the object of study were: Technology, Teaching Methodology, Teacher and Student. We conclude that in this new learning scenario the student is at the center of the process, the teacher is the mediator of knowledge, and therefore needs to show students that there are different ways to learn and build knowledge.

Keywords: Hybrid teaching. Role of the teacher in hybrid teaching. Technology in the educational process).

\section{Introdução}

A tecnologia faz parte do cotidiano de grande parte da sociedade nas atividades mais usuais, como o uso do computador, celular, tablet, bem como em atividades que eram essencialmente humanas, como nos atendimentos de lojas, bancos e nas compras, e desempenha papel relevante na sociedade. Isso, em parte, facilitou muitas ações; por outro lado, diminuiu postos de trabalho nas atividades repetitivas, sendo substituídas por robôs. No entanto, é inegável a mudança que a sociedade percebeu depois da revolução da informática, principalmente pela disseminação da informação e expansão da comunicação global (GIDDENS, 2012).

Segundo Kenski (2012 p. 22), “o surgimento de um novo tipo de sociedade tecnológica é determinado principalmente pelos avanços das tecnologias digitais de comunicação e informação e pela microeletrônica". A tecnologia possibilita ao homem desenvolver técnicas para facilitar seu trabalho e, principalmente, ampliar a comunicação em tempo real e imediato, independentemente das distâncias ou localidades onde as pessoas estejam. A tecnologia também está relacionada à educação e, para Niskier (1993), ela apresenta "uma mediação do encontro entre Ciência, Técnicas e Pedagogia." ou pode servir também como "um exercício crítico com utilização de instrumentos a serviço de um projeto pedagógico".

É importante salientar que a tecnologia também atua no desenvolvimento cognitivo, na formação de habilidades e no desempenho escolar. Valente (2011, p. 14) afirma que "a questão da aprendizagem efetiva, relevante e condizente com a realidade e atual configuração social se resume na composição de duas concepções: a informação que deve ser acessada e o conhecimento que deve ser construído pelo aprendiz". Sendo assim, o uso da tecnologia é uma ferramenta que proporciona acesso imediato e torna o aluno mais independente, ao ter que construir a compreensão do conhecimento após acessá-lo virtualmente.

Desta forma, há que se destacar que a tecnologia deve ser utilizada de maneira adequada, para que os ganhos positivos não sejam suplantados pelos negativos. Considerando como efeitos negativos o tempo no uso de máquinas e equipamentos por parte das crianças e dos jovens, quando estes diminuem a socialização e capacidade de envolvimento com atividades que não sejam aquelas virtualizadas. $\mathrm{O}$ uso 
exagerado das tecnologias também desconstrói o vínculo familiar e social das crianças e adolescentes que exercem um bom relacionamento com o mundo virtual, pois há um privilégio no uso dos equipamentos tecnológicos para comunicar-se em substituição às relações presenciais para bate-papos e passeios, entre outras atividades do cotidiano das relações pessoais (PAIVA, 2015; COSTA, 2015).

A proposta do ensino híbrido surgiu para contribuir com um novo olhar pedagógico, que apresenta aos educadores formas de integrar o uso das tecnologias digitais no currículo escolar que, por sua vez, combina com as interações presenciais. A proposta híbrida visa à personalização do ensino e da aprendizagem num modelo possível para facilitar a combinação do ensino presencial, que utiliza a mediação de um professor, e aquele on-line, em que a mediação é feita por tecnologia artificial. Nessa proposta o ensino colaborativo pode estar aliado ao uso das tecnologias digitais e propiciar uma aprendizagem significativa que ultrapassam as barreiras da sala de aula (MORAN e BACICH, 2015).

O presente artigo tem como proposta uma reflexão crítica comparativa entre o modelo de ensino tradicional, tecnológico e o Híbrido, A partir das abordagens sobre os modelos de ensino, foi possível fazer uma discussão sobre das habilidades necessárias que se espera para o processo de ensino-aprendizagem com ensino híbrido.

\subsection{Por que utilizar a tecnologia no processo educacional?}

As escolas não estão totalmente fora dos avanços tecnológicos; elas existem nas atividades burocráticas e nas atividades de ensino e aprendizagem; entretanto, nesta última, os avanços tenham sido menores. Coutinho e Lisboa (2011) afirmam que a escola e os seus agentes têm de mudar os métodos e técnicas de ensino e pensar em formas eficientes e eficazes para preparar os estudantes para a sociedade do conhecimento. A utilização da tecnologia no processo educacional torna-se, portanto, um desafio do momento.

É importante destacar que a tecnologia atua no desenvolvimento cognitivo das crianças, na melhoria e na formação de habilidades, e melhora o desempenho escolar. Para Gomes (2013, p. 155), "alguns aplicativos podem ajudar no desenvolvimento das capacidades cognitivas, auxiliando no aprendizado de cores, formas, na coordenação motora e no processo de alfabetização". Entretanto, é preciso pensar que há uma revolução tecnológica em andamento e em passos largos, enquanto a educação caminha muito lentamente nesse processo, principalmente porque os atores envolvidos ainda estão profissionalmente despreparados para enfrentar propostas mais ousadas nas escolas e universidades - "[...] a escola não pode ficar à margem do avanço tecnológico, sendo que o uso crítico e construtivo das Tecnologias de Informação e Comunicação deve ocorrer o quanto antes, ou seja, a partir da Educação Infantil" - contribui Gomes (2013, p. 152).

Uma vez que a tecnologia facilita a comunicação, o ensino híbrido pode facilitar a interação em adquirir conhecimentos nos diversos e distintos espaços educacionais e entre os mais diferentes lugares do campo, da cidade, das periferias e dos espaços afastados dos grandes centros urbanos, bem como das cidades pequenas - ou seja, a escola, ao incluir as ferramentas tecnológicas, pode ser ampliada com a troca de experiências entre os mais diversos e distintos espaços (PIRES, 2012), evitando reduzi-la aos limites das salas de aulas e seu entorno.

No entanto, para que se tenha um bom resultado com o Ensino Híbrido, é fundamental que os professores busquem novos papéis no ambiente escolar - não apenas como facilitadores da aprendizagem, mas principalmente por meio de novas abordagens pedagógicas, e seu uso deve ser intencional e planejado, com foco sempre na melhoria do aprendizado, de modo que a tecnologia possa interferir no cognitivo das crianças e jovens (GAROFOLO, 2019). 
Sendo assim, a construção de conhecimento envolverá aspectos importantes intra-escola (ambiente escolar, professores, estrutura escolar) e extra-escola (questão socioeconômica, estrutura familiar, grau de escolaridade familiar) e, neste momento, a tecnologia tem papel relevante na sociedade e, por isso, tem sido (deveria ser mais) introduzida no ambiente escolar. Na visão de Kenski (2011, p. 103), “O uso criativo das tecnologias pode auxiliar os professores a transformar o isolamento, a indiferença e a alienação com que costumeiramente os alunos frequentam as salas de aula, em interesse e colaboração".

\subsection{Ensino Híbrido}

O Ensino Híbrido, no entendimento de Morin (2015, p. 26), "significa misturado, mesclado, blended", e surgiu como uma possibilidade inovadora para alavancar e/ou viabilizar a qualidade de aprendizagem dos alunos, mas também, contribui no "planejamento das diferentes atividades para grupos de alunos, em ritmos distintos e com possibilidade real de acompanhamento pelos professores" (MORIN, 2015, p. 35).

Entretanto, o processo de ensino-aprendizagem de encontros presenciais em sala de aula tradicional não pode e nem deve ser abandonado porque há questões importantes que só o processo presencial processa e interfere numa aprendizagem completa e, unindo ambas as modalidades, sala tradicional e tecnológica, dentro de um contexto pedagógico construído e adequado, pode potencializar resultados bem melhores. No entanto, isso só se concretizará se o professor se apropriar de suas funções de liderança (WANDRESEN, 2011) e usá-las aliadas às finalidades a que se propõe o ensino híbrido.

O mundo atual está invadido de tecnologia de acesso à comunicação e à informação. Portanto, capturar essas tecnologias e incorporá-las em sala de aula tradicional, mantendo a interação social afetiva entre os colegas de turma e professores, pode produzir resultados importantes e inovadores na Educação. Todas essas transformações são de fundamental importância e urgentes para o momento, pois o impacto do avanço tecnológico se efetiva como processo social que atinge todas as instituições e espaços sociais ou privados - "invadindo a vida do homem no interior de sua casa, na rua onde mora, nas salas de aulas com os alunos". (DORIGONI; DA SILVA, 2013, p. 3).

Na premissa híbrida, os professores podem disponibilizar mais tempo para planejar suas aulas e se dedicar às posturas e habilidades requeridas para os alunos. Essa nova proposta metodológica não significa a resolução de todos os problemas educacionais, mas amplia a construção de uma prática pedagógica que potencializa o aprendizado dos alunos num contexto tecnológico contemporâneo sem abandonar o uso da sala de aula tradicional.

Essa forma híbrida oferece as vantagens da educação on-line combinadas com os benefícios do ensino presencial. Na opinião de Morin (2015), o ensino híbrido é uma tendência promissora e muito significativa na educação, devido às transformações sociais nas últimas décadas, que absorveram as ferramentas tecnológicas no cotidiano das pessoas. De acordo com HORN (2015), os modelos de ensino híbrido estão organizados em: modelos de Rotação; modelo Flex; modelo À la carte e modelo Virtual.

\section{Os modelos de Rotação compreendem:}

a) Rotação por estação - nessa estação, os alunos fazem um rodízio de acordo com a agenda do professor, sendo, pelo menos, uma delas, tarefas on-line, sendo que as demais podem ser atividades escritas em papel, pequenos projetos, instruções individualizadas e trabalhos em grupo;

b) Laboratório Rotacional é semelhante à Rotação por estação. Nessa estação, os estudantes são encaminhados para o laboratório de informática, para a parte do ensino on-line. A ideia, nesta estação, é liberar tempo dos professores e espaço da sala de aula, usando um laborató- 
rio de informática e uma estrutura de pessoal diferente para o acompanhamento on-line;

c) Salas de aulas invertidas - são assim denominadas porque invertem completamente a função normal da sala de aula; os estudantes têm lições ou palestras on-line, de forma independente, seja em casa ou durante o período de realização de tarefa; os estudantes ainda aprendem por meio de aulas expositivas e, muitas delas, em versões on-line como, por exemplo, vídeos caseiros;

d) Rotação individual - numa rotação individual, os estudantes alternam num esquema individualmente personalizado entre modalidades de aprendizagem. Um software, ou um professor, estabelece o cronograma de cada aluno, de acordo com suas necessidades individuais;

1. O Modelo Flex é uma modalidade em que os alunos se movem com flexibilidade com o computador ou em pequenos grupos;

2. O Modelo À la carte é a forma mais comum de ensino híbrido; pode ser utilizado em qualquer curso ou disciplina literalmente on-line, enquanto frequenta o ensino presencial;

3. O Modelo Virtual Enriquecido ocorre basicamente on-line; os encontros presenciais ocorrem de maneira agendada entre tutores e alunos (HORN, 2015, pp. 38-42).

A proposta do modelo híbrido necessita ser disruptiva, ou seja, deve oferecer inovações e modificações sem abolir o uso das salas de aulas tradicionais. Essa modalidade integra os modelos virtual e presencial, integrando-as de forma a contemplar o uso das tecnologias e mantendo as relações presenciais. No entanto, para que isso aconteça, é necessário investir na capacitação docente.

O padrão de inovação disruptiva contribui para integrar o ensino virtual em escolas e colabora para enfrentar os desafios da educação contemporânea que tem a necessidade de se adaptar a rotinas ligadas à tecnologia. Tajra (2011) afirma que a tecnologia atrai mais a atenção dos alunos e, além disso, eles ganham mais autonomia, ficam mais motivados, criativos, curiosos, e os estudantes com déficit de concentração tornam-se mais concentrados.

Os modelos de ensino híbridos proporcionam também o ensino personalizado. Este possibilita identificar o nível de dificuldade de cada aluno de forma individual ou em grupo, e é uma atividade que, se utilizada por meio da tecnologia, possibilita um atendimento educacional bastante especifico para cada aluno ou grupo sem sobrecarregar o professor. Neste caso, o professor utilizará a tecnologia com as ferramentas de interfaces das webs para colaborar no seu trabalho, que antes era manual. Esta é uma das grandes tendências educacionais que contribuem para as metodologias inovadoras.

Sobre o ensino personalizado, Moran (2015, p. 42) salienta que a junção de metodologias ativas com tecnologias digitais permite o desenvolvimento de uma aprendizagem melhor, através de práticas, atividades, jogos, problemas e projetos que combinem na colaboração e personalização no contexto em que estão inseridos. Ainda, segundo o mesmo autor, as tecnologias atingiram o ápice e envolvem toda a população mundial, sendo que elas permitem ampliar um novo conceito de sala de aula, de espaço, de tempo e realidades diversas. 


\subsection{Alguns Pressupostos para o Papel do Professor no Ensino Híbrido na Aprendizagem Personalizada}

Com a chegada do século XXI, surgiram novas implicações sociais, políticas, econômicas, culturais e, principalmente, educacionais. Nesse período, a sociedade vem buscando um novo significado de conhecimento para as áreas sociais. Com o advento da tecnologia, a sociedade mercadológica buscou, na educação, suporte teórico e prático, o que levou Kenski (2012 p. 22) a afirmar que "o surgimento de um novo tipo de sociedade tecnológica é determinado principalmente pelos avanços das tecnologias digitais de comunicação e informação e pela microeletrônica."

Diante de frequentes mudanças sociais, politicas, econômicas, tecnológicas e principalmente culturais, a educação nesse contexto não pode ser fragmentada, é necessário romper com as fragmentações metodológicas e avançar em busca de conhecimento, visto que a tecnologia é crescente. Para Rolkouski (2011, p. 87): “[...] o papel da tecnologia no processo ensino-aprendizagem subentende uma concepção do que vem a ser o aprender e o ensinar", e ainda acrescenta: “O uso da tecnologia está além do 'fazer melhor', 'fazer mais rápido', trata-se de um 'fazer diferente"' (ROLKOUSKI, 2011, p. 102).

Além dos pressupostos já citados, Imbérnon (2010, p. 36) destaca que "o professor deve abandonar a ideia de que é preciso sempre ensinar algo para que os alunos aprendam". Ou seja, deve abrir caminho para que as TIC signifiquem uma transformação educativa fazendo o papel e expor conceitos, e assim o professor deve assumir com mais ênfase o papel de mediador do conhecimento em suas práticas de ensino.

Na aprendizagem dentro do modelo híbrido, a função do professor é apenas de facilitador; não é função do professor responder às perguntas dos alunos, até porque as respostas estão na internet e nos livros, “o papel do professor não é tecnológico, mas intelectual, fornecendo ao aluno contexto, assegurando qualidade e ajuda individualizada" (PRENSKY, 2010, p. 203).

A escola é um dos locais de aprendizagem, e não o único; a educação deve ser entendida como um fator de realização da cidadania, com padrões de qualidade da oferta e do produto, na luta contra a superação das desigualdades sociais e da exclusão social (LIBÂNEO, 2012, p. 133).

O aprendizado é feito com a mediação do professor, deixando ao aluno o papel de testar, errar, e procurar a resposta correta. Nesse sentido, Masetto (2010, p.175) define que "o papel do professor em uma aula é o de mediação pedagógica e, da forma como ele desempenhar este papel de mediador, o emprego de técnicas pode ter maior ou menor sucesso para a aprendizagem dos alunos". O foco não é mais o conteúdo, e sim a habilidade que precisa gerar em seus alunos para aplicar o conhecimento. Desta forma, o professor, além de ser educador e transmissor de conhecimento, deve atuar e ser a ponte entre o estudante e o conhecimento, para que o aluno aprenda a "pensar" (BULGRAEN, 2010, p. 31).

Há ainda alguns aspectos importantes que devem ser considerados no ensino híbrido: identificar categorias que os alunos necessitam aprender; o professor deve dominar o conteúdo; utilizar e descobrir as habilidades cognitivas e as habilidades não cognitivas; o professor deve assumir que tem uma bagagem repleta de histórias e de modelos.

É importante que o professor descreva os objetivos e separe um tempo especifico para que os alunos trabalhem nessas atividades e nos processos; os alunos devem receber um feedback claro, seja dos conteúdos ou das habilidades cognitivas ou não cognitivas; cada aluno recebe avaliação individual, para que saibam exatamente o que estão fazendo bem e em que precisam de investimento em aprendizagem. Diante do exposto, Berbel (2011, p. 25) contribui com a seguinte reflexão:

"a complexidade crescente dos diversos setores da vida no âmbito mundial, nacional e local tem demandado o desenvolvimento de capacida- 
des humanas de pensar, sentir e agir de modo cada vez mais amplo e profundo, comprometido com as questões do entorno em que se vive."

Nessa direção, é necessário deixar o professor colocar na prática o seu talento, porque, de acordo com Cardoso (2012, p. 2), "a prática reflexiva é a busca de equilíbrio entre o ato de rotina e o ato de reflexão".

\section{Metodologia}

A partir da literatura existente sobre ensino híbrido, TORI (2009) afirma que o ensino híbrido é referenciado na literatura por meio de inúmeras denominações, destacando-se com o termo blended learning, cuja tradução mais aceita para o português é ensino híbrido. Para os autores Horn e Staker (2015, p.54) “o ensino híbrido é o motor que pode tornar possível à aprendizagem centrada no estudante para alunos do mundo todo, em vez de apenas alguns privilegiados."

Tendo em vista as afirmações dos autores, criou-se uma matriz de análise composta pelos indicadores de dez habilidades que se pretende alcançar com o ensino e pelas abordagens de educação: tradicional é compreendido como a Educação exclusiva com a mediação docente, tecnológica se relaciona ao uso de tecnologias de comunicação e aplicativos de Educação a Distância- EAD e híbrida é aquela que não abandona a mediação do professor e faz uso das diversas tecnologias disponíveis. A análise permitiu produzir um resultado quantitativo, ou seja, a análise consiste em determinar um valor numérico que a abordagem de educação produz na habilidade.

Esta transformação foi utilizada com o uso da Escala Likert, por ser um instrumento científico de observação e mensuração de fenômenos sociais idealizadas com a finalidade de medir as atitudes por meio das opiniões de forma objetiva (LIKERT, 1932).

A Escala Likert permite a transformação de informações qualitativas em quantitativas, ou seja, os valores 1, 2, 3, 4 e 5 foram usados para medir o resultado por meio de concordância, portanto, 5 é valor para que o indicador tenha maior ocorrência na abordagem pedagógica, e 1, a menor ocorrência. O somatório de cada modelo de ensino é um indicativo preliminar da maior possibilidade de maior sucesso daquele modelo educacional para produções das habilidades desejadas para uma educação de qualidade.

A avaliação foi realizada na disciplina Política de Desenvolvimento, no Programa de Pós-Graduação em Desenvolvimento Regional e Meio Ambiente/PGDRA/UNIR, com participação de oito discentes (discentes de mestrado e doutorado, professores do ensino Médio Federal, de ensino Superior Federal e particular) no momento da discussão sobre a interferência da Educação no processo de Desenvolvimento da Região Amazônica. A avaliação das habilidades foi realizada por cada um dos integrantes e o valor apresentado foi à média das respostas.

Os indicadores utilizados são: I Espírito de liderança, II- Consciência crítica, ética e moral, III - Aprender a viver e conviver em sociedade, IV- Forma consciente, ativa, participativa, V- Diferenciando bem de mal, VI- Cidadão íntegro e de respeito, VII- Letramento, VIII- Autonomia, IX- Habilidades matemáticas, X- Habilidade profissional.

\section{Resultados e Discussão}

O quadro a seguir relaciona as habilidades necessárias para o processo de aprendizagem com os modelos educacionais tendo como concordância os dez indicadores de habilidades cognitivas. 
Quadro 1: Habilidades necessárias para o aprendizado e modelos educacionais

\begin{tabular}{|c|c|c|c|}
\hline $\begin{array}{l}\text { Indicadores/ } \\
\text { habilidades } \\
\text { Cognitivas }\end{array}$ & Tradicional & Uso de tecnologia & Ensino híbrido \\
\hline Espírito de liderança & $\begin{array}{l}1 \\
\text { A atuação do professor } \\
\text { como foco da formação } \\
\text { não permite que o aluno } \\
\text { se torne pró-ativo. }\end{array}$ & $\begin{array}{l}3 \\
\text { O aluno é independente, } \\
\text { entretanto pode não se } \\
\text { tornar e não ser incenti- } \\
\text { vado a sê-lo. }\end{array}$ & $\begin{array}{l}5 \\
\text { O professor é mode- } \\
\text { rador, podendo assim } \\
\text { incentivar a habilidade. }\end{array}$ \\
\hline $\begin{array}{l}\text { Consciência crítica, } \\
\text { ética e moral }\end{array}$ & $\begin{array}{l}\mathbf{5} \\
\text { O professor pode levar o } \\
\text { aluno a pensar critica- } \\
\text { mente sobre o papel da } \\
\text { educação na vida e na } \\
\text { sociedade. }\end{array}$ & $\begin{array}{l}1 \\
\text { Não há ação neste } \\
\text { sentido, porque o } \\
\text { aprendizado é isolado. }\end{array}$ & $\begin{array}{l}3 \\
\text { O professor pode levar } \\
\text { o aluno a construir a } \\
\text { criticidade; entretanto, só } \\
\text { se estiver nos objetivos } \\
\text { do professor. }\end{array}$ \\
\hline $\begin{array}{l}\text { Aprender a viver e } \\
\text { conviver em } \\
\text { sociedade }\end{array}$ & $\begin{array}{l}3 \\
\text { A postura do mestre não } \\
\text { proporciona a criação de } \\
\text { vínculos. }\end{array}$ & $\begin{array}{l}1 \\
\text { Pelo contrário, esta } \\
\text { atividade pode produzir } \\
\text { isolamento. }\end{array}$ & $\begin{array}{l}\mathbf{5} \\
\text { Este pode ser um } \\
\text { objetivo da } \\
\text { aprendizagem. }\end{array}$ \\
\hline $\begin{array}{l}\text { Forma consciente, } \\
\text { ativa, participativa }\end{array}$ & $\begin{array}{l}2 \\
\text { O professor limita as } \\
\text { ações do grupo. }\end{array}$ & $\begin{array}{l}1 \\
\text { A atividade é individual e } \\
\text { não há incentivo. }\end{array}$ & $\begin{array}{l}\mathbf{5} \\
\text { A tecnologia pode atuar } \\
\text { como complemento à } \\
\text { ação do professor para } \\
\text { atingir o objetivo. }\end{array}$ \\
\hline $\begin{array}{l}\text { Diferenciando bem } \\
\text { de mal }\end{array}$ & $\begin{array}{l}3 \\
\text { O professor pode atuar } \\
\text { com esse objetivo ético. }\end{array}$ & $\begin{array}{l}1 \\
\text { Não há, na tecnologia, } \\
\text { capacidade para criar } \\
\text { esse aprendizado. }\end{array}$ & $\begin{array}{l}\mathbf{5} \\
\text { O professor e a } \\
\text { tecnologia podem estar } \\
\text { a serviço para atingir o } \\
\text { objetivo ético. }\end{array}$ \\
\hline $\begin{array}{l}\text { Cidadão íntegro } \\
\text { e de respeito }\end{array}$ & $\begin{array}{l}3 \\
\text { O professor pode atuar } \\
\text { com esse objetivo ético. }\end{array}$ & $\begin{array}{l}1 \\
\text { Não, há na tecnologia, } \\
\text { capacidade para criar } \\
\text { esse aprendizado. }\end{array}$ & $\begin{array}{l}\mathbf{5} \\
\text { O professor e a } \\
\text { tecnologia podem estar } \\
\text { a serviço para atingir o } \\
\text { objetivo ético. }\end{array}$ \\
\hline Letramento & $\begin{array}{l}3 \\
\text { A abordagem é mais de } \\
\text { repetição. }\end{array}$ & $\begin{array}{l}\mathbf{5} \\
\text { A tecnologia auxilia e } \\
\text { obriga a leitura e a escri- } \\
\text { ta com mais intensidade. }\end{array}$ & $\begin{array}{l}\mathbf{5} \\
\text { Tecnologia auxilia e obri- } \\
\text { ga a leitura e escrita com } \\
\text { mais intensidade. }\end{array}$ \\
\hline Autonomia & $\begin{array}{l}1 \\
\text { O ambiente não é } \\
\text { adequado para criar } \\
\text { autonomia, porque o } \\
\text { processo é centralizado } \\
\text { na figura do professor. }\end{array}$ & $\begin{array}{l}\mathbf{4} \\
\text { A tecnologia permite } \\
\text { a autonomia; entretanto, } \\
\text { pode construir } \\
\text { problemas com a } \\
\text { autonomia exacerbada. }\end{array}$ & $\begin{array}{l}\mathbf{5} \\
\text { A tecnologia permite a } \\
\text { autonomia; entretanto, } \\
\text { pode a autonomia } \\
\text { exacerbada ser mediada } \\
\text { pelo professor. }\end{array}$ \\
\hline $\begin{array}{l}\text { Habilidades } \\
\text { matemáticas }\end{array}$ & $\begin{array}{l}2 \\
\text { O processo é baseado na } \\
\text { repetição e em decorar. }\end{array}$ & $\begin{array}{l}\mathbf{5} \\
\text { A tecnologia interfere nas } \\
\text { habilidades matemáticas. }\end{array}$ & $\begin{array}{l}\mathbf{5} \\
\text { A tecnologia interfere nas } \\
\text { habilidades matemáticas. }\end{array}$ \\
\hline $\begin{array}{l}\text { Habilidade } \\
\text { profissional }\end{array}$ & $\begin{array}{l}2 \\
\text { A formação é centrada } \\
\text { na repetição de ações }\end{array}$ & $\begin{array}{l}\mathbf{4} \\
\text { A tecnologia permite a } \\
\text { busca e exercícios para } \\
\text { absorver habilidades; } \\
\text { entretanto, é individual. }\end{array}$ & $\begin{array}{l}\mathbf{5} \\
\text { A tecnologia permite } \\
\text { a busca e a prática de } \\
\text { exercícios para absorver } \\
\text { habilidades; o mediador } \\
\text { pode indicar caminhos } \\
\text { mais propícios. }\end{array}$ \\
\hline TOTAL & 24 & 22 & 48 \\
\hline
\end{tabular}


A partir do Quadro 1 e, compreendendo as limitações desses indicadores, propomos comparar as habilidades com as práticas pedagógicas, visando criar uma análise capaz de jogar luz aos resultados das várias abordagens, considerando que os resultados são apenas indicativos.

Nos resultados, estão descritos como o modelo consegue ou não alcançar e/ou desenvolver as habilidades/indicadores. Como já destacado neste texto, o ensino híbrido é aquele que tem maior possibilidade de que se alcancem as diversas habilidades e a única que não teve nota máxima foi consciência crítica, ética e moral, porque nesta habilidade se requer uma opção política por parte do professor, e esta pode não estar nos objetivos do docente. Nesta abordagem, a contagem chegou a 48 pontos de um total de 50, o que perfaz $96 \%$.

No ensino tradicional, as habilidades mais valorizadas são aquelas que estão focadas na atuação do professor. Nesta abordagem, a contagem obtida foi de 24 pontos em 50, perfazendo $48 \%$.

No ensino puramente tecnológico, todas as habilidades tiveram performance baixa, porque o ensino é isolado, sem interação e, sobretudo, não há socialização e construção de objetivos que poderiam ser mediados pelo professor. Nesta abordagem, a contagem obtida foi de 22 pontos de um total de 50, perfazendo apenas $44 \%$.

As práticas do ensino e aprendizagem são distintas nas diversas abordagens, tanto no ensino com a sala de aula tradicional e uso de tecnologia - híbrido. Entretanto, para a referência de análise, buscaram-se alguns pontos da aprendizagem para a vida cotidiana do aluno: letramento, autonomia, criticidade, relação com o mundo exterior, sociabilidade, habilidade matemática e exercício da cidadania.

De acordo com Gasparin (2001, p. 8), o pensar e o fazer, o emocional e o intelectual, estão entrelaçados, de maneira que estão inteiros em cada coisa que os alunos fazem". Anastasiou (2006, p. 14) reforça ser importante entender um pouco melhor quem são os alunos enquanto pessoas com sonhos, aspirações e até desesperanças, pois dessa maneira serão planejadas atividades nas quais eles se sintam convocados a "fazer aulas" com o professor.

É possível observar nos resultados a reflexão sobre desempenho do aluno nos três modelos de ensino: tradicional, tecnológico, híbrido. Mesmo os resultados apontando positivamente que o ensino mediado pelas tecnologias com o suporte do ensino híbrido está contribuindo para aquisição de conhecimento, colocando o aluno como protagonista nesse novo cenário de ensino, é importante ressaltar que as novas metodologias não diminuem o papel do professor em sala de aula; pelo contrário, elas contribuem e agregam conhecimento entre professor e aluno. De acordo com Kenski:

Na era da informação, comportamentos, práticas, informações e saberes se alteram com extrema velocidade. Um saber ampliado e mutante caracteriza o estágio do conhecimento na atualidade. Essas alterações refletem-se sobre as tradicionais formas de ensinar e aprender possibilitadas pela atualidade tecnológica. Abrir-se para novas educações, resultantes de mudanças estruturais de ensinar e aprender possibilitadas pela atualidade tecnológica é o desafio a ser assumido por toda sociedade. (KENSKI, 2012, p. 41).

Outro fator de relevância que precisa ser considerado é que os recursos tecnológicos e novos métodos de articular a aprendizagem dos alunos não resolvem todos os problemas do ensino. Os benefícios da tecnologia na aprendizagem começam a ser conquistados se a escola for considerada como um todo, analisando as possibilidades, os limites e os entraves, para se tornar realmente um espaço de inclusão social e digital, levando, de fato, as crianças e jovens a aprenderem mais e melhor (VOSGERAU, 2011). 


\section{Conclusão}

A proposta do ensino híbrido tem como intenção colocar o aluno como o centro das atividades. Criar uma cultura certa é fundamental para que esse novo modelo de ensino seja bem-sucedido; é uma forma de trabalhar em conjunto com os alunos e alcançar objetivos comuns. Portanto, o projeto político-pedagógico da escola precisa se reformular para integrar as tecnologias digitais, de forma que o aluno possa aprender significativamente em um novo ambiente, que agora contempla o presencial e o digital.

Sendo assim, inserir modelos educacionais com ferramentas tecnológicas no ensino proporciona mudanças significativas na aprendizagem, além de contribuir nas mudanças no papel dos professores e traçar/determinar as diferenças entre o que os alunos aprendem melhor por meio dos softwares e de forma isolada, com o professor orientando na forma virtual e presencial.

O quadro analítico que relacionou as habilidades e os modelos de ensino demonstrou que o modelo híbrido pode produzir resultados importantes na incorporação das habilidades no aprendizado do aluno, quando comparado a outros modelos.

Assim, como pressuposto nesse novo cenário, a proposta para o professor deve ser: de orador para facilitador; de generalista para especialista; de estrutura de grupos fixos para estratégias mais dinâmicas de agrupamento; deixar de ser quem explica, apesar de intervir no momento certo, conforme a necessidade; deixar de focar no conteúdo apenas, para concentrar-se em conteúdos e habilidades, e até na postura dos alunos.

\section{Referências}

BERBEL N. N. A. As metodologias ativas e a promoção da autonomia de estudantes. Seminário: Ciências Sociais e Humanas, 32 (1), p. 25-40, 2011.

BULGRAEN, V. C. O papel do professor e sua mediação nos processos de elaboração do conhecimento. Revista Conteúdo, Capivari, v.1, n.4, ago./dez. 2010.

CARDOSO, C. A. Formação crítico-reflexiva: a relação teoria e prática. Integração: ensino, pesquisa, extensão, ano VIII, n 30, agosto de 2012.

COUTINHO, C.; LISBOA, E. "Sociedade da informação, do conhecimento e da Aprendizagem: desafios para educação no século XXI". Revista de Educação, Vol. XVIII, n.1, p 5-22, 2011.

DORIGONI, G. M. L.; DA SILVA, J. C. Mídia e Educação: o uso das novas tecnologias no espaço escolar. v. 10, p. 12, 2013.

GAROFALO, D. 7 ideias para usar a tecnologia na Educação infantil. Revista Nova Escola, abril de 2019. Disponível em: <https://novaescola.org.br/conteudo/16856/7-ideias-para-usar-a-tecnologia-na-educacao-infantil>. Acesso: 29 de abril de 2019.

ANASTASIOU, L. das G. C.; ALVES, L. P.(orgs.). Processos de ensinagem na universidade: pressupostos para as estratégias de trabalho em sala de aula. 6. Ed. - Joinville, SC: UNIVILLE, 2006.

GASPARIN, J. L. Motivar para aprendizagem significativa. Jornal Mundo Jovem. Porto Alegre, n. 314, p. 8, mar. 2001. 20 Uma didática para a pedagogia histórico-crítica. 4. ed. rev. e ampl. - Campinas, SP: Autores Associados, 2007.

GIDDENS, A. Sociologia. 6. Ed. Porto Alegre: Penso, 2012. 
GOMES, S. dos S. Brincar em Tempos Digitais. In: Revista Presença Pedagógica - Diálogo entre Universidade e Educação Básica para Formação do Professor. Seção Presença Infantil. Belo Horizonte, n. 113, p. 44-51. set./out. 2013.

HORN, M. B.; STAKER, H. Blended: usando a inovação disruptiva para aprimorar a educação. Trad. De M Cristina G. Monteiro. Porto Alegre: Penso 2015.

IMBERNÓN, F. Formação docente e profissional: formar-se para a mudança e a incerteza. 7. Ed. São Paulo: Cortez, 2010.

KENSKI, V.M. Educação e Tecnologias o Novo Ritmo da Informação. Editora Papirus. Campinas, SP, $8^{\circ}$ edição, 2011.

KENSKI, V. M. Educação e tecnologias: Um novo ritmo da informação. 8. ed. Campinas: Papirus, 2012. p. $15-25$.

LIBÂNEO, J. C.; OLIVEIRA, J. F. de; ITHOSCHI, M. S. Educação Escolar: Políticas, Estrutura e Organização. 10. ed. São Paulo: Cortez, 2012.

LIKERT, R. A Technique for the Measurement of Attitudes. Archives of Psychology, v. 140, p. 1-55, 1932. MASETTO, M. T. O professor na hora da verdade. São Paulo: Avercamp, 2010

MORIN, E. Os sete saberes necessários à educação do futuro. Tradução de Catarina Eleonora F. da Silva e Jeanne Sawaya.2. ed.São Paulo: Cortez, Brasília, 2011. Vol. II. P. 15-33. 2015.

.Edgar. Introdução ao pensamento complexo. 3. ed. Porto Alegre: Sulina, 2007.

MORAN, J. Educação Híbrida: um conceito-chave para a educação, hoje. In: BACICH, L.; NETO, A. T.; TREVISANI, F. de M. (Orgs.). Ensino híbrido: personalização e tecnologia na educação. Porto Alegre: Penso, 2015.

MORAN, J. M. Mudando a educação com metodologias ativas. In: SOUZA, C. A. de; MORALES, O. E. T. (Org.). Coleção Mídias Contemporâneas. Convergências Midiáticas, Educação e Cidadania: aproximações jovens. Vol. II. PG: Foca FotoPROEX/UEPG, 2015.

NISKIER, A. Tecnlogia Educacional uma visão política. Petrópolis: vozes, 1993.

PAIVA, N. M. N.;COSTA, J. da S. A influência da tecnologia na infância: desenvolvimento ou ameaça? IN: Psicologia. Net. 2015.

PIRES, A. M. Educação do campo como direito humano. São Paulo: Cortez, 2012.

PRENSKY, M. 0 papel da tecnologia no ensino e na sala de aula. In: Conjectura. v. 15, n. 2, p.201-204, maio/ago. 2010.

ROLKOUSKI, E. Tecnologias no ensino de Matemática. Curitiba: Ibpex, 2011.

TAJRA, S. F. Informática na Educação, São Paulo: Érica,2011.

TORI, R. Cursos híbridos ou blended learning. In: LITTO, F.; FORMIGA, M. Educação a distância: o estado da arte. São Paulo: Pearson Educacional do Brasil, 2009.

VALENTE, J. A. Educação a distância: pontos e contrapontos. São Paulo: Summus, 2011. 
VOSGERAU, D. S.R. A tecnologia na escola: o papel do gestor neste processo. In: BARBOSA, A. F. (coord). TIC Educação 2011: pesquisa sobre o uso das tecnologias de informação e comunicação nas escolas brasileiras. São Paulo. 2012, p 35-41.

WANDRESEN, A. S. R. Web 2.0 e educação: Uso e Possibilidades. In: X congresso nacional de educação - educere, 2011, Curitiba. I Seminário Internacional de Representações Sociais, Subjetividade e Educação - SIRSSE. Curitiba: PUCPR, 2011. p. 12658 - 12667. 